\title{
The Impact of Diabetes on Cutaneous \\ Leishmanisis: A Case Control Study on Infection, Treatment Outcomes and its Public Health Importance
}

\section{Mahshid Mostafavi}

Kerman University of Medical Sciences

Iraj Sharifi ( $\square$ iraj.sharifi@yahoo.com )

Kerman University of Medical Sciences

Gholamreza Asadikaram

Kerman University of Medical Sciences

Nozar Nakhaee

Kerman University of Medical Sciences

\section{Sina Kakooei}

Kerman University of Medical Sciences

Mohammad Reza Aflatoonian

Kerman University of Medical Sciences

\section{Mehdi Bamorovat}

Kerman University of Medical Sciences

\section{Razieh Tavakoli Oliaee}

Kerman University of Medical Sciences

Ali Karamoozian

Kerman University of Medical Sciences

Research article

Keywords: Diabetes, Cutaneous leishmaniasis, Co-infection, Risk factors

Posted Date: July 15th, 2020

DOI: https://doi.org/10.21203/rs.3.rs-42482/v1

License: (c) (1) This work is licensed under a Creative Commons Attribution 4.0 International License. Read Full License 


\section{Abstract}

Background: The aim of this study was to assess the associated-risk determinants for cutaneous leishmaniasis (CL) in patients with diabetes mellitus (DM) compared to patients without diabetes.

Methods: This work was performed as a case-control study between 2016 and 2019 in southeastern Iran. Participants were selected from patients with $D M$ without $C L$, patients with $C L$ without $D M$, and $D M$ patients co-infected with CL as case groups and healthy individuals as a control group. The groups were screened, interviewed, and clinically examined. These cases were compared for parasitological, immunological, biochemical, and hematological parameters. T-test, univariate, multivariate logistic regression, univariate and multivariate multinomial logistic regression analyses were performed to compare the inter- and intra-subgroups. $P<0.05$ was defined significant.

Results: The findings demonstrated that parasitological factors regarding the number, duration, and size of the lesion in CL patients showed a significant difference among patients with and without diabetes ( $p$ $<0.05$ ). Data analysis showed that six major risk factors, including female (odds ratio $(O R)=3.47$, confidence interval $(\mathrm{Cl})=1.84-6.53, p<0.001)$, total protein in $\mathrm{CL}$ group $(\mathrm{OR}=4.9, \mathrm{Cl}=2.3-10.44, p<0.001)$, alanine aminotransferase (ALT) concentration in $\mathrm{CL}$ group ( $\mathrm{OR}=0.87, \mathrm{Cl}=0.81-0.93, p<0.001)$ and $\mathrm{DM}$ coinfected with $\mathrm{CL}$ group $(\mathrm{OR}=0.8, \mathrm{Cl}=0.72-0.88, p<0.001)$ than healthy group, aspartate aminotransferase (AST) concentration in DM group ( $\mathrm{OR}=0.86, \mathrm{Cl}=0.76-0.98, p=0.02)$, transforming growth factor beta )TGF- $\beta$ ( level in the $\mathrm{CL}$ group $(\mathrm{OR}=1.03, \mathrm{Cl}=1.003-1.05, p=0.02)$ and presence of diabetes disease $(\mathrm{OR}=$ 2.07, $\mathrm{Cl}=1.16-3.7, p<0.05)$ were significantly linked with the induction of $\mathrm{CL}$ lesion. Furthermore, the parasitological, immunological, biochemical, and hematological findings were different from the $\mathrm{CL}$ group to DM co-infected with CL group.

Conclusions: The findings demonstrated that there was a significant relationship between DM and CL in distinct risk determinants. Also, the study revealed that DM enhanced the severity of active CL. Therefore, proper prophylactic and therapeutic measures should be taken in endemic countries where DM and CL are co-infected.

\section{Background}

Diabetes mellitus (DM) is emergent health problem worldwide. It is a common metabolic disease that leads to complications and morbidity, decreases the quality of life, and even causes death in patients when there are other underlying concomitant infections $[1,2]$. The global number of diabetes was estimated to be $2.8 \%$ ( 171 million) in 2000 . This figure is estimated to the extent $4.4 \%$ (366 million) in 2030 [3]. With the prevalence rate of over $9.4 \%$ in 2019, Iran has the highest rate of diabetes in the world. Diabetes is the ninth and third leading cause of death among humans in Iran and in the world, respectively [1, 4]. According to an estimate by the World Health Organization (WHO), if effective action is not taken to prevent diabetes, the number of people suffering from this disease will increase to 7 million by 2030 in Iran. 
On the other hand, leishmaniasis represents a serious public health concern in about 100 countries [5]. This disease is both neglected and vector-borne caused by over 20 species belonging to the genus Leishmania which is transmitted by female sand flies [6]. Clinical presentations consist of three classical forms; cutaneous (CL), visceral, and mucocutaneous leishmaniasis (MCL). These forms constitute a broad spectrum of benign, self-healing to fatal forms if left untreated. $C L$ is the most widespread form which comprises about three-fourths of the overall case counts [7]. The annual reported cases are estimated at 1-1.5 million cases; of which $90 \%$ are reported from Iran, Iraq, Peru, Afghanistan, Algeria, Syria, Saudi Arabia, and Brazil [8]. Recent estimates show that the burden of CL is due to the present conflicts and resultant migration in the world, notably in the Middle East Countries. Currently, the number of cases has remarkably risen and reached a hyperendemic level by a factor of 6 to 10 [9].

In Iran, two species of the old world of Leishmania are present: anthroponotic CL (ACL) caused by $L$. tropica, which exists primarily in medium and large sized-cities. Here humans are the main carriers and Phlebotomus sergenti is the principal vector [10-13]. Zoonotic $C L(Z C L)$ is caused by $L$. major which is frequently present in rural areas in gerbils and $P$. papatasi is the major vector [10]. CL has recently seen a significant rise and expansion into new geographical zones in Iran and abroad because of various risk factors [11].

This pandemic of DM involves not only the industrialized nations but also less-developed countries where urbanization and industrialization are proceeding rapidly [14]. The population of developing countries, minority groups, and disadvantaged communities in industrialized countries are now at the greatest risk [15].

Many studies showed that there was a relation among DM and tuberculosis [16], such as a systematic review which revealed that the risk of tuberculosis between people with DM is three times higher than in people without DM [17]. Based on the previous studies, neutrophils from people with DM decreased chemotaxis and oxidative killing potential more than those without DM [18], also leukocyte bactericidal activity was decreased in diabetic people, mainly people with negligible glucose control [19]. So, DM straightly impairs the innate and adaptive immune responses to infectious diseases. Hence, the coexistence of $\mathrm{CL}$ and diabetes is high particularly in endemic countries. It is clear that DM imposes a substantial impact on the present and future burden of CL. The main reasons for the little attention to coinfection spatially DM and CL are the diverse and its mutual interactions, complex, and difficult to understand $[20,21]$

The present study was planned as no investigation has previously been carried out on this subject. Literature is silent and there is virtually no study material available about concomitant infections of diabetes and Leishmania agent, the two most common and growing diseases. Therefore, the objective of this survey was to reveal the impact of diabetes on infection, treatment outcomes, and clinical implication of cutaneous leishmanisis.

\section{Methods}




\section{Participants and methods}

\section{Ethical consideration}

Before the survey began, several meetings were held with the inhabitants, community leaders, and health authorities to describe the aim, procedures, and the potential benefits in planning future preventive and therapeutic programs. The complete informed consent of all volunteers was obtained. Also, informed consent was obtained from a parent or guardian for participants under 16 years old. All the participants were well aware of the study plan and objectives and only candidates who were interested to participate in the study and signed the consent sheet were enrolled. The survey protocol was reviewed and approved by the joint Ethics Committees of the Leishmaniasis Research Center and Vice-Chancellor for Research, Kerman University of Medical Sciences (No. 95/230). Detected patients were treated with appropriate drugs and if required referred to higher hospital levels for further check-ups and follow-up assessments.

\section{Sampling and design}

This work was performed as a case-control study between 2016 and 2019 in major ACL foci in Bam and Kerman districts. The patients were randomly selected from the diabetes registry of health centers and also from $\mathrm{CL}$ control clinics in Bam and Kerman Counties. Participants were selected from patients with DM without $C L$, patients with $C L$ without $D M$, and DM patients co-infected with $C L$ as case groups and healthy individuals as a control group. The groups were screened, interviewed, and clinically examined.

\section{Patients with diabetes}

In this study, patients with type 2 diabetes were defined as persons who had fasting blood sugar (FBS) more than $125 \mathrm{mg} / \mathrm{dl}$, hemoglobin A1C (HbA1c) higher than 6.5 DCCT \% and oral glucose tolerance test (OGTT) more than $200 \mathrm{mg} / \mathrm{dl}$. All of the patients with diabetes had a history of the disease and were previously registered and routinely referred to the centers for diabetes in Kerman and Bam counties (Table 1).

Table 1

Parameters of patients with type 2 diabetes.

\begin{tabular}{|lll|}
\hline Parameters & Mean & Normal rang \\
\hline Fasting blood sugar (FBS) & $168.57(\mathrm{mg} / \mathrm{dl})$ & $100-125(\mathrm{mg} / \mathrm{dl})$ \\
\hline Hemoglobin A1C (HbA1C) & $8.02(\%)$ & $>5.7(\%)$ \\
\hline Oral glucose tolerance test (OGTT) & $236.01(\mathrm{mg} / \mathrm{dl})$ & $<140(\mathrm{mg} / \mathrm{dl})$ \\
\hline
\end{tabular}

\section{Inclusion and exclusion criteria}

The participants with an age range of 15-85 years old were included, but those with a history of acute diseases, HIV disease, pregnant, and lactating women were excluded.

\section{Parasitological examination}


Tissue scrapings were taken from the margin of active cutaneous lesions by scalpel and blade, smeared on a glass slide, air dried, methanol fixed, stained by Giemsa, and microscopically examined for the amastigote stage (Leishman bodies). For each patient, a questionnaire was completed and demographic and clinical data were recorded.

\section{Hematological examination}

Five $\mathrm{ml}$ blood samples were taken and $0.5 \mathrm{ml}$ injected into tubes containing EDTA, stored at $4{ }^{\circ} \mathrm{C}$ and analyzed within $8 \mathrm{~h}$. Complete blood count (white blood cells (WBC), red blood cell (RBC), hemoglobin (HGB), mean corpuscular hemoglobin ( $\mathrm{MCH})$, and mean corpuscular volume (MCV) were performed using a fully automated hematology analyzer Sysmex Kx-21 (Sysmex Corporation, Japan). The remaining blood portion was kept in a refrigerator for at least 30 minutes. Serum samples were then detached by centrifugation at 3,000 RPM for $3-5$ minutes and stored at $-70^{\circ} \mathrm{C}$ for measuring cytokines and biochemical parameters.

\section{Immunological examination}

Plasma concentrations of transforming growth factor beta (TGF- $\beta$ ), Interferon-gamma (IFN- $\gamma$ ), Interleukin (TGF- $\beta$ ), Interferon-gamma (IFN- $\gamma$ ), Interleukin (IL)-4 were measured by ELISA kits (R\&D Systems, USA) according to the manufacturer's instructions. All the standard safety precautions were taken during the experimental procedures.

\section{Biochemical examination}

Aspartate aminotransferase (AST), alanine transaminase (ALT), alkaline phosphatase (ALP), cholesterol, total protein, and albumin levels were measured by a commercial kit (Pars Azmoon Company, Iran) by using an automated analyzer (Technicon Company, RA1000 model, USA).

\section{Statistical analysis}

Data were entered into SPSS (version 20) software (Chicago, IL, USA). T-test, univariate, multivariate logistic regression, univariate, and multivariate multinomial logistic regression analysis were performed to compare various. Univariate multinomial logistic regression was used to assess if the variables were suitable to be used in multiple multinomial logistic regressions. At last, variables with $p$-value less than 0.2 were picked after the analysis. The major cause of using the multiple methods was to exclude the confounders. To further control the confounders, the backward elimination stepwise method was applied to obtain the finest possible model. $P<0.05$ was considered statistically significant.

\section{Results}

\section{Demographic characters}

Overall, 206 participants including 57 (27.6\%) DM co-infected with CL, 44 (11.2\%) DM, 41 (6.2\%) CL patients, and $64(76 \%)$ healthy individuals were precisely analyzed for parasitological, hematological, 
biochemical and immunological parameters. In the diabetic patients, overall had underlying chronic diseases such as eyes (39\%), heart (18\%), kidney (39\%), nerve (16\%), blood pressure $(32 \%)$ and blood fat (21\%) which some of them had multiple diseases ( $40 \%$ of diabetic patients had underlying chronic diseases). The presence of such chronic diseases in patients with ACL is an inevitable event. There wasn't any significant difference between base-line characteristics in four groups (Table 2).

Table 2

Baseline characteristics of study participant

\begin{tabular}{|c|c|c|c|c|}
\hline Characteristics & $\begin{array}{l}\mathrm{DM}+\mathrm{CL} \\
\text { No (\%) }\end{array}$ & $\begin{array}{l}\text { DM } \\
\text { No (\%) }\end{array}$ & $\begin{array}{l}\text { CL } \\
\text { No (\%) }\end{array}$ & $\begin{array}{l}\text { Healthy } \\
\text { No (\%) }\end{array}$ \\
\hline \multicolumn{5}{|l|}{ Sex } \\
\hline Male & $14(24.6)$ & $9(22)$ & $10(22.7)$ & $29(45.3)$ \\
\hline Female & $43(75.4)$ & $32(78)$ & $34(77.3)$ & $35(54.7)$ \\
\hline \multicolumn{5}{|l|}{ Age (year) } \\
\hline$<30$ & $8(14)$ & $11(26.8)$ & $6(13.6)$ & 11(17) \\
\hline $30-50$ & $30(52.6)$ & $18(43.9)$ & $17(38.6)$ & $32(50)$ \\
\hline$>50$ & $19(33.4)$ & $12(29.3)$ & $21(47.8)$ & $21(33)$ \\
\hline Total & 57 & 41 & 44 & 64 \\
\hline \multicolumn{5}{|c|}{ CL; Patients with cutaneous leishmaniasi } \\
\hline DM; Patients wi & diabetes & & & \\
\hline
\end{tabular}

\section{Univariate vs. multivariate analyses}

The univariate regression analysis showed the odds of developing $\mathrm{CL}$ in patients with $\mathrm{DM}(\mathrm{OR}=2.02, \mathrm{Cl}=$ $1.16-3.52, p<0.05)$ were significantly higher than those without $\mathrm{DM}$. Infection of $\mathrm{CL}$ in females $(\mathrm{OR}=$ $3.14, \mathrm{Cl}=1.83-6.35, p<0.001)$ displayed significantly higher odds than males.

The multivariate regression model confirmed identical major risk determinants comprising of female (OR $=3.47, \mathrm{Cl}=1.84-6.53, p<0.001)$ than male and patients with $\mathrm{DM}(\mathrm{OR}=2.07, \mathrm{Cl}=1.16-3.7, p<0.05)$ compared to patients without $\mathrm{DM}$. These factors were significantly associated-risk determinants for $\mathrm{CL}$ patients (Table 3). 
Table 3

Potential risk determinants for cutaneous leishmaniasis in patients with diabetes and patients without diabetes.

\begin{tabular}{|lllllll|}
\hline Risk Factors & OR & Univariate 95\% Cl & P-value & OR & Multivariate 95\% Cl & P-value \\
\hline Age & & & & & & \\
\hline$\geq 40$ & 1.98 & $0.25-1.03$ & $>0.05$ & - & - & - \\
\hline$<40$ & 1 & & & & & \\
Sex & & & & & $<0.001$ \\
\hline Female & 3.14 & $1.83-6.35$ & $<0.001$ & 3.47 & $1.84-6.53$ & \\
Male & 1 & & 1 & & $<0.05$ \\
\hline Diabetes & & & & & & \\
\hline Yes & 2.02 & $1.16-3.52$ & $<0.05$ & 2.07 & $1.16-3.7$ & \\
\hline No & 1 & & & 1 & \\
\hline There wasn't any significant difference between base-line characteristics in four groups.
\end{tabular}

\section{Parasitological parameters}

The results showed that parasitological factors such as number, size, and duration of lesions in CL patients co-infected with DM significantly different than patients without DM $(p<0.05)$ (Table 4). The mean duration of lesions in CL patients co-infected with DM was three times greater than in patients without DM. Our findings showed that the majority of the patients exhibited a history of CL already exhibited DM.

Table 4

Parasitological factors for cutaneous leishmaniasis in patients with diabetes and patients without diabetes.

\begin{tabular}{|llll|}
\hline Parasitological factors & DM + CL & CL & $P$ value \\
\hline Number of lesion & 2.02 & 1.5 & $<0.05$ \\
\hline Duration of lesion (month) & 9.4 & 3.3 & $<0.05$ \\
\hline Size of lesion(cm) & 1.84 & 1.31 & $<0.05$ \\
\hline DM; Patients with diabetes & & & \\
\hline CL; Patients with cutaneous leishmaniasis & \\
\hline
\end{tabular}

\section{Hematological parameters}

Based on the univariate logistic regression analysis, the odds of total hemoglobin concentration in $\mathrm{CL}$ group $(\mathrm{OR}=0.69, \mathrm{Cl}=0.51-0.93, p=0.01)$ or $\mathrm{DM}$ co-infected with $\mathrm{CL}$ group $(\mathrm{OR}=0.65, \mathrm{Cl}=0.48-0.89, p=$ 
0.008) were significantly lower than the healthy group (Table 5). 
Table 5

Univariate and multiple multinomial logistic regression analyses for parasitological, immunological and biochemical risk related-factors: odds ratio of diabetic group (DM), cutaneous leishmaniasis group (CL) and DM co-infected with $\mathrm{CL}(\mathrm{DM}+\mathrm{CL})$ compared to healthy people in southeastern Iran

\begin{tabular}{|c|c|c|c|c|c|c|c|}
\hline \multirow[t]{2}{*}{ Group } & \multirow[t]{2}{*}{ Variable } & \multicolumn{3}{|c|}{ Univariate logistic regression } & \multicolumn{3}{|c|}{ Multinomial logistic regression } \\
\hline & & OR & $\% 95 \mathrm{Cl}$ for OR & P-value & OR & $\% 95 \mathrm{Cl}$ for OR & P-value \\
\hline \multirow[t]{14}{*}{$\mathrm{CL}$} & Age & 1.007 & $0.97-1.04$ & 0.69 & & & \\
\hline & Sugar & 1.009 & $0.98-1.03$ & 0.48 & 0.98 & $0.94-1.02$ & 0.38 \\
\hline & Cholesterol & 1.008 & $0.99-1.02$ & 0.06 & & & \\
\hline & Protein total & 2.84 & $1.77-4.55$ & $<0.001$ & 4.72 & $2.13-10.47$ & $<0.001$ \\
\hline & Albumin & 1.14 & $0.68-1.91$ & 0.62 & & & \\
\hline & AST & 1.007 & $0.98-1.03$ & 0.50 & 1.07 & $1.005-1.14$ & 0.03 \\
\hline & ALT & 0.91 & $0.87-0.95$ & $<0.001$ & 0.88 & $0.83-0.94$ & $<0.001$ \\
\hline & ALP & 1.01 & $1.004-1.02$ & 0.002 & & & \\
\hline & WBC & 0.87 & $0.72-1.05$ & 0.14 & & & \\
\hline & RBC & 1.16 & $0.54-2.48$ & 0.70 & & & \\
\hline & Hemoglobin & 0.69 & $0.51-0.93$ & 0.01 & & & \\
\hline & INF-Y & 1.01 & $1.002-1.02$ & 0.016 & & & \\
\hline & TGF- $\beta$ & 1.03 & $1.009-1.06$ & 0.006 & 1.03 & $1.003-1.05$ & 0.02 \\
\hline & IL-4 & 1.02 & $1.01-1.03$ & 0.001 & & & \\
\hline \multirow[t]{7}{*}{ DM } & Age & 1.07 & $1.04-1.11$ & $<0.001$ & & & \\
\hline & Sugar & 1.11 & $1.07-1.15$ & $<0.001$ & 1.11 & $1.06-1.17$ & $<0.001$ \\
\hline & Cholesterol & 1.006 & $0.99-1.01$ & 0.20 & & & \\
\hline & Protein total & 1.08 & $0.66-1.75$ & 0.76 & 1.02 & $0.56-1.88$ & 0.93 \\
\hline & Albumin & 0.73 & $0.28-1.89$ & 0.51 & & & \\
\hline & AST & 1.004 & $0.97-1.03$ & 0.74 & 0.86 & $0.76-0.98$ & 0.02 \\
\hline & ALT & 1.005 & $0.99-1.01$ & 0.46 & 0.98 & $0.87-1.11$ & 0.79 \\
\hline
\end{tabular}

AST: Aspartate Aminotransferase ALT:Alanine Aminotransferase

ALP: Alkaline Phosphatase WBC: White Blood Cell

RBC: Red Blood Cell TGF- $\beta$ : Transforming growth factor beta

IL: Interleukin INF: Interferon 


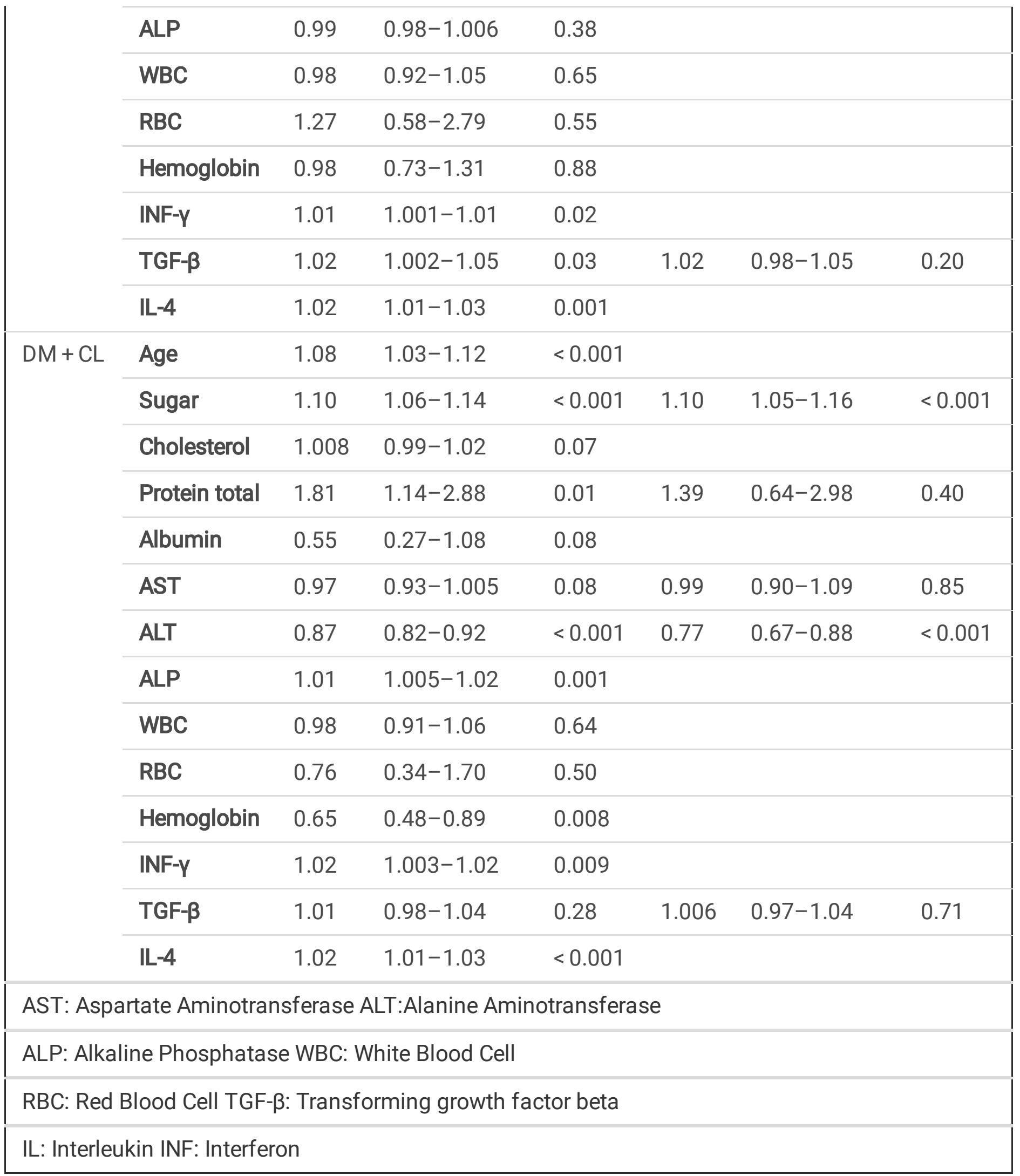

\section{Biochemical parameters}

According to the univariate logistic regression analysis, the odds of AST concentration in the CL group (OR $=1.06, \mathrm{Cl}=1.003-1.12, p=0.04)$ were significantly higher than the healthy group and the odds of AST concentration in DM group $(\mathrm{OR}=0.88, \mathrm{Cl}=0.75-0.98, p<0.02)$ were significantly lower than the 
healthy group. Also the concentration of ALP in DM co-infected with $C L$ group $(\mathrm{OR}=1.01, \mathrm{Cl}=1.004-1.02$, $p=0.002)$ or $\mathrm{CL}$ group $(\mathrm{OR}=1.01, \mathrm{Cl}=1.005-1.02, p=0.001)$ were significantly higher than the healthy group (Table 5).

Regarding to the multinomial logistic regression analysis, the odds of ALT concentration in CL group (OR $=0.87, \mathrm{Cl}=0.81-0.93, p<0.001)$ or DM co-infected with $\mathrm{CL}$ group $(\mathrm{OR}=0.8, \mathrm{Cl}=0.72-0.88, p<0.001)$ were significantly lower than the healthy group. The odds of AST concentration in $\mathrm{CL}$ group $(\mathrm{OR}=1.07, \mathrm{Cl}$ $=1.005-1.14, p=0.03$ ) were significantly higher than the healthy group and the odds of AST concentration in $\mathrm{DM}$ group $(\mathrm{OR}=0.86, \mathrm{Cl}=0.76-0.98, p=0.02)$ were significantly lower than the healthy group. Total protein in $\mathrm{CL}$ group $(\mathrm{OR}=4.9, \mathrm{Cl}=2.3-10.44, p<0.001)$ were significantly higher than the healthy group (Table 5).

\section{Immunological parameters}

Based on the univariate logistic regression analysis, the odds of TGF- $\beta$ level in $C L$ group $(O R=1.03, \mathrm{Cl}=$ $1.003-1.05, p=0.02)$ or $\mathrm{DM}$ group $(\mathrm{OR}=1.02, \mathrm{Cl}=1.002-1.05, p=0.03)$ were significantly higher than the healthy group. The level of IL-4 in DM group (OR $=1.02, \mathrm{Cl}=1.01-1.13, p=0.001), \mathrm{CL}$ group $(\mathrm{OR}=1.02, \mathrm{Cl}$ $=1.01-1.06, p=0.001)$ or $\mathrm{DM}$ co-infected with $\mathrm{CL}$ group $(\mathrm{OR}=1.02, \mathrm{Cl}=1.003-1.02, p=0.009)$ were significantly higher than the healthy group. The level of IFN- $y$ in $C L$ group $(\mathrm{OR}=1.01, \mathrm{Cl}=1.002-1.02, p=$ $0.016)$, $\mathrm{DM}$ group $(\mathrm{OR}=1.02, \mathrm{Cl}=1.01-1.03, p=0.03)$ or $\mathrm{DM}$ co-infected with $\mathrm{CL}$ group $(\mathrm{OR}=1.02, \mathrm{Cl}=$ $1.003-1.02, p=0.009$ ) were significantly higher than the healthy group (Table 5).

According to the multinomial logistic regression analysis, the odds of TGF- $\beta$ level in the CL group (OR = $1.03, \mathrm{Cl}=1.003-1.05, p=0.02$ ) was significantly higher than the healthy group (Table 5).

\section{Discussion}

To the best of our knowledge, this is the first study on the relation between DM and CL as evaluated by clinical and systematic intrinsic factors in recent years in the world. Patients with DM contract infections more frequently than those without DM $[20,21]$. The risk of many serious health problems and infectious diseases is significantly increased in patients with a history of chronic diseases such as DM, HIV/AIDS, tuberculosis, and opium addiction [22, 23]. Some of these infections have a complicated course in patients with DM in comparison to patients without DM [24]. The present study showed that there was a positive association between $C L$ and two factors namely; female and DM as analyzed by the multivariate model. Previous reports showed that distinct risk determinants in opium-addicted participants in terms of size, number, and duration of the CL lesion were more severe than the non-opium-addicted group [13]. In our study, the lesions in terms of duration and size were significantly more severe and the duration of the lesion was three times longer in patients with DM compared to the patients without DM. The possible reasons for the difference are intrinsic evidence supporting the idea that DM induces direct impairment of cell-mediated immune response. This might in turn lead to the chronicity and severity of the lesions [20]. In mixed infections, the burden of both diseases increases. It is obvious that there are some levels of immune suppression in patients with DM. These may provide a suitable condition for the proliferation of 
the superimposed CL causative agent. Therefore, it is possible to explain such interactions in terms of the effect of the Leishmania species on the immune system. These include parasite-induced immune depression, as translated via cytokines generation[25]. Indeed, the importance of these interactions is extremely harmful and induce some disorders for co-infected patients. In addition, Leishmania species are able to produce secretory and excretory factors that can intensify the multiplication rate in an immunosuppressed individual as documented in HIV/AIDS and DM co-infections [22]. In our study, the risk of CL affliction in females and elderly people was highest and this could be attributed to the incidence of some chronic diseases such as DM. This caused defects in cellular innate immunity more frequently in female and elderly subjects compared to others [26].

During the early invasion by Leishmania parasite, the $T$ cells and the resultant cytokines play a critical role in determining the nature of the immune response and the outcome of the infection. In experimental leishmaniasis, the cure is related to the predominance of a Th-1 response, as this progresses to the production of IFN- $\gamma$ and stimulation of amastigote infected macrophages. In contrast, disease

progression is associated with the development of the Th-2 response. Consequently, IL-4, IL-10, IL-13, and TGF- $\beta$ are generated and leading to the inactivation of infected macrophages [27-31].

Several investigations have reported that cytokine imbalance is enhanced in type 2 diabetes [32]. This disease is mainly involved with Th-2 to Th- 1 immune response trend [33]. IL-4 is a Th-2 cytokine that suppresses cellular immunity [34]. In contrast, IFN-y is a Th-1 cytokine tsupports the immune system to perform cytolysis of the target cells [35]. In this study, the immunological examination of IL-4, IFN- $\gamma$, TGF$ß$ were significantly different between the groups. DM patients co-infected with $C L$ and DM had the lowest level of IFN- $y$ compared to other groups, therefore the odds of infection in DM co-infected with CL group are higher than the other groups. The levels of IL-4 and TGF- $ß$ were increased in CL patients and DM co-infected with $\mathrm{CL}$. The reason for this variation is not well understood; although, it could be related to the effect of parasite infection in CL patients.

In a hematology examination, only hemoglobin was at a significant level between different groups as patients with $C L$ and $D M$ had the least level. Females had the lowest level of hemoglobin in comparison to men [36]. Biochemical parameters including ALP, ALT, and AST were significantly different among groups. The exact reason for such differences is not well-known. However, the variability could be explained by the complexity of the natural interaction between diseases [21].

The causative agent in the areas under study was $L$. tropica causing ACL which is transmitted via an anthroponotic cycle. Essentially, DM co-infected with ACL patients can lead to clinical and epidemiological changes that modify the routine patterns of CL. Co-infected patients harbor many organisms in their skin lesions. Therefore, DM patients co-infected with ACL become a highly infectious reservoir of $\mathrm{CL}$ disease and ultimately resulting in increased risks of future epidemics.

The strength of this study was the diabetic and CL treatment centers with strong registry systems and appropriate infrastructures, which manage the patients via a team of expert and well-trained, physicians and experienced health surveillance personnel and with highly equipped diagnostic laboratory services. 
There are certainly a few inevitable potential limitations regarding the possibility of residual cofounders to this study such as other chronic diseases that might coexist with $\mathrm{DM}$, logical reasons for not entering all biological intrinsic factors (immunological, biochemical, and hematological parameters) in the logistic regression models.

\section{Conclusions}

The findings clearly demonstrated a significant relationship between DM and CL. Also, the study declared that DM increases the severity of active CL. In the present study, six major risk factors, including sex, total protein, ALT, AST, TGF- $\beta$, and presence of DM disease were significantly linked with the development of $\mathrm{CL}$ lesion. The number, size, and duration of lesions in the $\mathrm{CL}$ group were significantly different between patients with DM and without DM. The mean duration of a lesion in DM co-infected with the CL group was three times greater than in the $\mathrm{CL}$ group. The monitoring of patients with $\mathrm{DM}$ in $\mathrm{CL}$ endemic areas is extremely vital. Therefore, proper prophylactic and therapeutic measures should be implemented by physicians and health surveillance personnel where DM and CL are co-existed particularly in endemic foci. Since, DM is a common chronic disease in Iran where also $C L$ is endemic, protecting persons from being bitten by vectors is a critical and important measure for the prevention of co-infected and refractory forms of ACL caused by L. tropica in southeastern Iran.

\section{Abbreviations}

$\mathrm{L}$

Leishmania; DM:Diabetes mellitus; CL:Cutaneous leishmaniasis; OR:Odds atio; Cl:Confidence interval; AST:Aspartate aminotransferase; ALT:Alanine aminotransferase; ALP:Alkaline phosphatase; WBC:White blood cell; RBC:Red blood cell; TGF- $\beta$ :Transforming growth factor beta, IL:Interleukin, INF:Interferon.

\section{Declarations}

\section{Ethics approval and consent to participate}

The survey protocol was reviewed and approved by the joint Ethics Committees of the Leishmaniasis Research Center and Vice-Chancellor for Research, Kerman University of Medical Sciences, under protocol number $95 / 230$. The participants signed a consent sheet. Informed consent was obtained from a parent or guardian for participants under 16 years old.

\section{Consent for publication}

Not applicable.

\section{Competing interests}

The authors declare that they have no competing interests 


\section{Funding}

This work was financially supported by a grant No. 95/230 from Kerman University of Medical Sciences. The funders had no role in study design, data collection and analysis, decision to publish, or preparation of the manuscript.

\section{Authors' contributions}

ISh administered and supervised the work. GhA, ISh and MM conceived and designed the experiments. SK and MM performed the experiments. NN, MM and MRA analyzed and interpreted the patient data. MM, and SK wrote the first draft of the paper. ISh, MB, and RTO reviewed and corrected the paper. All authors reviewed and approved the manuscript.

\section{Acknowledgements}

We would like to express our heartfelt thanks to the health personnel of the Bam Health Center. Special thanks to Dr. Dabiri and Mr.Karimi and also Kerman University of Medical Sciences that helped in carrying out this study.

\section{Availability of data and materials}

The datasets used and/or analyzed during the current study are available from the corresponding author on reasonable request.

\section{References}

1. Khaledi S, Moridi G, Gharibi F. Survey of eight dimensions quality of life for patients with diabetes type II, referred to Sanandaj diabetes center in 2009. J Fasa Univ Med Sci. 2011;1:29-37. http://journal.fums.ac.ir/browse.php?a_code=A-10-26-10\&slc_lang=en\&sid=1. Accessed 18 Apr 2018.

2. Seuring T, Archangelidi O, Suhrcke M. The Economic Costs of Type 2 Diabetes: A Global Systematic Review. Pharmacoeconomics. 2015;33:811-31. doi:10.1007/s40273-015-0268-9.

3. Wild S, Roglic G, Green A, Sicree R, King H. Global prevalence of diabetes: estimates for the year 2000 and projections for 2030. Diabetes Care. 2004;27:1047-53. http://www.ncbi.nlm.nih.gov/pubmed/15111519. Accessed 18 Apr 2018.

4. Mahmoudi A. Effects of self care planning on reduction of A1C hemoglobin in adults with diabetes mellitus. Med Sci J Islam Azad Univesity - Tehran Med Branch. 2006;16:171-6. http://iautmuj.ir/browse.php?a_id=119. Accessed 18 Apr 2018.

5. Reithinger R, Dujardin J-C, Louzir H, Pirmez C, Alexander B, Brooker S. Cutaneous leishmaniasis. Lancet Infect Dis. 2007;7:581-96. doi:10.1016/S1473-3099(07)70209-8.

6. Minodier P, Parola P. Cutaneous leishmaniasis treatment. 2006. doi:10.1016/j.tmaid.2006.09.004. 
7. Murray HW, Berman JD, Davies CR, Saravia NG. Advances in leishmaniasis. Lancet. 2005;366:156177. doi:10.1016/S0140-6736(05)67629-5.

8. Desjeux P. Leishmaniasis: current situation and new perspectives. Comp Immunol Microbiol Infect Dis. 2004;27:305-18. doi:10.1016/J.CIMID.2004.03.004.

9. Bailey F, Mondragon-Shem K, Hotez P, Ruiz-Postigo JA, Al-Salem W, Acosta-Serrano Á, et al. A new perspective on cutaneous leishmaniasis-Implications for global prevalence and burden of disease estimates. PLoS Negl Trop Dis. 2017;11:e0005739. doi:10.1371/journal.pntd.0005739.

10. Karimi A, Hanafi-Bojd AA, Yaghoobi-Ershadi MR, Akhavan AA, Ghezelbash Z. Spatial and temporal distributions of phlebotomine sand flies (Diptera: Psychodidae), vectors of leishmaniasis, in Iran. Acta Trop. 2014;132:131-9. doi:10.1016/j.actatropica.2014.01.004.

11. Sharifi I, Aflatoonian MR, Fekri AR, Hakimi Parizi M, Aghaei Afshar A, Khosravi A, et al. A comprehensive review of cutaneous leishmaniasis in kerman province, southeastern iran-narrative review article. Iran J Public Health. 2015;44:299-307.

http://www.ncbi.nlm.nih.gov/pubmed/25905072. Accessed 17 Apr 2018.

12. Saghafipour A, Rassi Y, Abai M, Oshaghi M. Outbreak of zoonotic cutaneous leishmaniasis: A report. 2013. http://jhygiene.muq.ac.ir/files/site1/user_files_6ceac6/admin-A-10-1-36-91b41f3.pdf. Accessed 18 Apr 2018.

13. Aflatoonian MR, Sharifi I, Hakimi Parizi M, Fekri AR, Aflatoonian B, Sharifi M, et al. A Prospective Cohort Study of Cutaneous Leishmaniasis Risk and Opium Addiction in South Eastern Iran. PLoS One. 2014;9:e89043. doi:10.1371/journal.pone.0089043.

14. Amos AF, McCarty DJ, Zimmet P. The rising global burden of diabetes and its complications: estimates and projections to the year 2010. Diabet Med. 1997;14 Suppl 5:S1-85. http://www.ncbi.nlm.nih.gov/pubmed/9450510. Accessed 18 Apr 2018.

15. Zimmet P. Globalization, coca-colonization and the chronic disease epidemic: can the Doomsday scenario be averted? J Intern Med. 2000;247:301-10. http://www.ncbi.nlm.nih.gov/pubmed/10762445. Accessed 18 Apr 2018.

16. Jiménez-corona ME, Cruz-hervert LP, García-garcía L, Ferreyra-reyes L, Delgado-sánchez G, Bobadilladel-valle $\mathrm{M}$, et al. Association of diabetes and tuberculosis: impact on treatment and post-treatment outcomes. 2013;:-214-20.

17. Jeon CY, Murray MB. Diabetes Mellitus Increases the Risk of Active Tuberculosis: A Systematic Review of 13 Observational Studies. PLoS Med | www. 2008;5:1091. doi:10.1371/journal.pmed.0050152.

18. MC MDDMMM. LG, H A, B G. Impaired leucocyte functions in diabetic patients. Diabet Med. 1997;14:29-34.

19. Feinstein AR, Walter SD, Horwitz RI. An analysis of Berkson's bias in case-control studies. J Chronic Dis. 1986;39:495-504.

20. Geerlings SE, Hoepelman Al. Immune dysfunction in patients with diabetes mellitus (DM). FEMS Immunol Med Microbiol. 1999;26:259-65. http://www.ncbi.nlm.nih.gov/pubmed/10575137. 
Accessed 25 Apr 2018.

21. Sison JP, Kemper CA, Loveless M, McShane D, Visvesvara GS, Deresinski SC. Disseminated acanthamoeba infection in patients with AIDS: case reports and review. Clin Infect Dis. 1995;20:1207-16. http://www.ncbi.nlm.nih.gov/pubmed/7620001. Accessed 25 Apr 2018.

22. Matima R, Murphy K, Levitt NS, BeLue R, Oni T. A qualitative study on the experiences and perspectives of public sector patients in Cape Town in managing the workload of demands of HIV and type 2 diabetes multimorbidity. PLoS One. 2018;13:e0194191.

doi:10.1371/journal.pone.0194191.

23. Deresinski S. Infections in the diabetic patient: Strategies for the clinician. Infect Dis Rep. 1995;1:112.

24. Bamorovat M, Sharifi I, Aflatoonian MR, Sharifi H, Karamoozian A, Sharifi F, et al. Risk factors for anthroponotic cutaneous leishmaniasis in unresponsive and responsive patients in a major focus, southeast of Iran. PLoS One. 2018;13:e0192236. doi:10.1371/journal.pone.0192236.

25. Cox FE. Concomitant infections, parasites and immune responses. Parasitology. 2001;122 Suppl:S23-38. http://www.ncbi.nlm.nih.gov/pubmed/11442193. Accessed 25 Apr 2018.

26. Rider V, Gubbels Bupp MR, Bupp GM, Potluri T, Fink AL, Klein SL. The Confluence of Sex Hormones and Aging on Immunity. Immunity Front Immunol. 2018;9:1269. doi:10.3389/fimmu.2018.01269.

27. Etges R, Müller I. Progressive disease or protective immunity to Leishmania major infection: the result of a network of stimulatory and inhibitory interactions. J Mol Med (Berl). 1998;76:372-90. http://www.ncbi.nlm.nih.gov/pubmed/9625295. Accessed 25 Apr 2018.

28. Reiner SL, Locksley RM. The Regulation of Immunity to Leishmania Major. Annu Rev Immunol. 1995;13:151-77. doi:10.1146/annurev.iy.13.040195.001055.

29. Melby PC. Experimental leishmaniasis in humans: review. Rev Infect Dis. 13:1009-17. http://www.ncbi.nlm.nih.gov/pubmed/1962075. Accessed 25 Apr 2018.

30. da Silva DAM, Santana FR, Katz S, Garcia DM, Teixeira D, Longo-Maugéri IM, et al. Protective Cellular Immune Response Induction for Cutaneous Leishmaniasis by a New Immunochemotherapy Schedule. Front Immunol. 2020;11 March:1-12.

31. Dubie T. Review Article Review on the Role of Host Immune Response in Protection and Immunopathogenesis during Cutaneous Leishmaniasis Infection. 2020;2020.

32. Nosratabadi R, Arababadi MK, Hassanshahi G, Yaghini N, Pooladvand V, Shamsizadeh A, et al. Evaluation of IFN-gamma serum level in nephropatic type 2 diabetic patients. Pakistan J Biol Sci PJBS. 2009;12:746-9. http://www.ncbi.nlm.nih.gov/pubmed/19634484. Accessed 25 Apr 2018.

33. Skopiński P, Rogala E, Duda-Król B, Lipińska A, Sommer E, Chorostowska-Wynimko J, et al. Increased interleukin-18 content and angiogenic activity of sera from diabetic (Type 2) patients with background retinopathy. J Diabetes Complications. 2005;19:335-8.

doi:10.1016/j.jdiacomp.2005.02.008.

34. Bid HK, Konwar R, Agrawal CG, Banerjee M. Association of IL-4 and IL-1RN (receptor antagonist) gene variants and the risk of type 2 diabetes mellitus: a study in the north Indian population. Indian $\mathrm{J}$ 
Med Sci. 2008;62:259-66. http://www.ncbi.nlm.nih.gov/pubmed/18688110. Accessed 25 Apr 2018.

35. Stalenhoef JE, Alisjahbana B, Nelwan EJ, Ven-Jongekrijg J, Ottenhoff THM, Meer JWM, et al. The role of interferon-gamma in the increased tuberculosis risk in type 2 diabetes mellitus. Eur $\mathrm{J}$ Clin Microbiol Infect Dis. 2008;27:97-103. doi:10.1007/s10096-007-0395-0.

36. Rushton DH, Dover R, Sainsbury AW, Norris MJ, Gilkes JJH, Ramsay ID. Why should women have lower reference limits for haemoglobin and ferritin concentrations than men? BMJ. 2001;322:13557.

\section{Figures}

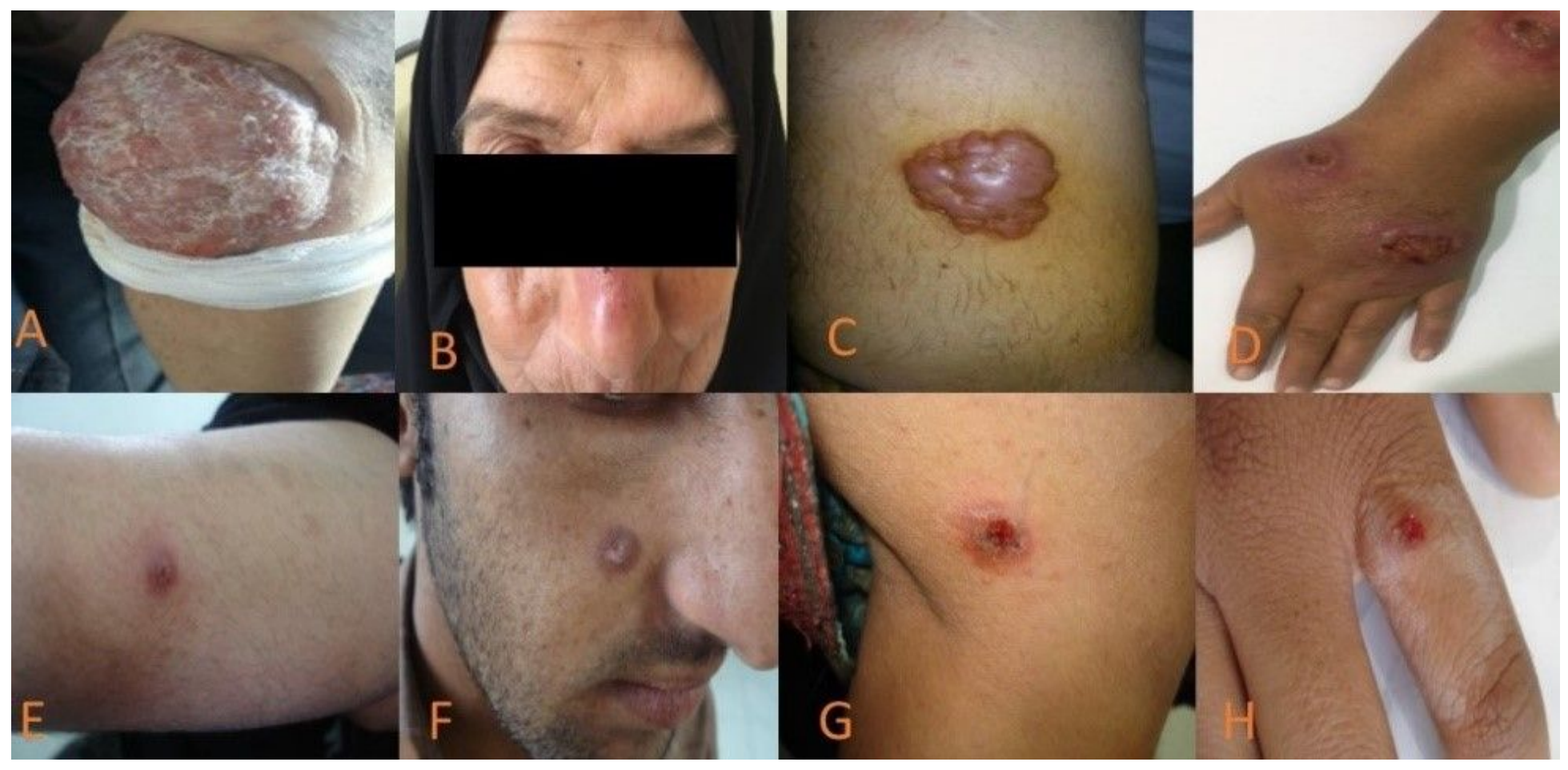

\section{Figure 1}

Representative pictures of skin lesions taken from diabetics (A-D) and non-diabetic patients $(E-H)$ in endemic areas with $\mathrm{CL}$ in southeastern Iran.

\section{Supplementary Files}

This is a list of supplementary files associated with this preprint. Click to download.

- TableSupplementary.docx 